\title{
Analysis of apoptosis related genes in nurses exposed to anti-neoplastic drugs
}

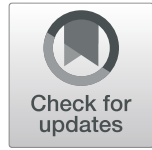

\author{
Maral Ramazani ${ }^{1}$, Razieh Pourahmad Jaktaji ${ }^{2}$, Farshad H. Shirazi ${ }^{1,5}$, Maria Tavakoli-Ardakani ${ }^{3}$, Ahmad Salimi ${ }^{4 *}$ and \\ Jalal Pourahmad ${ }^{1 *}$ (D)
}

\begin{abstract}
Background: Anti-neoplastic agents are widely used in the treatment of cancer and some non-neoplastic diseases. These drugs have been proved to be carcinogens, teratogens, and mutagens. Concern exists regarding the possible dangers of the staff handling anti-cancer drugs. The long-term exposure of nurses to anti-neoplastic drugs is still a controversial issue. The purpose of this study was to monitor cellular toxicity parameters and gene expression in nurses who work in chemotherapy wards and compare them to nurses who work in other wards.

Methods: To analyze the apoptosis-related genes overexpression and cytotoxicity effects, peripheral blood lymphocytes obtained from oncology nurses and the control group.

The results: Significant alterations in four analyzed apoptosis-related genes were observed in oncology nurses. In most individual samples being excavated, BCl-2 overexpression is superior to that of Bax. Prominent P53 and Hif-1a up-regulation were observed in oncology nurses. Moreover, all cytotoxicity parameters (cell viability, ROS formation, MMP collapse, Lysosomal membrane damage, Lipid peroxidation, Caspase 3 activity and Apoptosis phenotype) in exposed oncology nurses were significantly $(p<0.001)$ higher than those of unexposed control nurses. Upregulation of three analyzed apoptosis-related genes were observed in nurses occupationally exposed to anticancer drugs.
\end{abstract}

Conclusion: Our data show that oxidative stress and mitochondrial toxicity induced by anti-neoplastic drugs lead to overexpression of apoptosis-related genes in oncology nurses.

Keywords: Nurse, Apoptosis, Gene analysis, Mitochondria, Anti-neoplastic drugs

\section{Background}

Chemotherapy is an important method for cancer treatment that is used for anti-cancer drugs to cure patients. Anti-neoplastic drugs are extremely active biological compounds and their actions are non-selective [1]. Previous studies showed the possible dangers there to the staff handling anti-cancer drugs [2, 3]. Mutagenic and carcinogenic effects of anti-cancer drugs were shown in 1969 by the International Agency for Research on Cancer $[4,5]$. Mutagenesis, chromosomal damages, skin hyperpigmentation, abortion, premature birth, and abnormal pregnancies are shown in that people who are in

\footnotetext{
*Correspondence: j.pourahmadjaktaji@utoronto.ca

${ }^{4}$ Department of Pharmacology and Toxicology, School of Pharmacy, Ardabil University of Medical Sciences, Ardabil, Iran

'Department of Pharmacology and Toxicology, Faculty of Pharmacy, Shahid Beheshti University of Medical Sciences, Tehran, Iran

Full list of author information is available at the end of the article
}

contact with anti-neoplastic drugs [3]. Anticancer drugs can also produce reactive oxygen species (ROS) which purportedly leads to mutations and DNA damage. Overproduction of ROS can affect lipids, protein, and DNA of the cell and lead to destroying the structure and function of cells [6]. At low doses, ROS had been associated with induction of cell survival signaling pathways, whilst at high doses activate death signaling through apoptosis and necrosis [7]. Oxygen-free radicals activate the tumor suppressor protein p53 at lower doses causes DNA repair, cell cycle arrest, and senescence. Well, if damages were very intense, p53 can control apoptosis transcriptionally by up-regulating pro-apoptotic members such as Bax, Bid, Puma, Noxa and Apaf-1, DR-4, FasL, Fas and DR-5 and down-regulating pro-survival proteins such as IAPs, Bcl-XL, Bcl-2 and surviving [8]. In the cytosol, P53 can translocate to mitochondria and interact straightly

(c) The Author(s). 2019 Open Access This article is distributed under the terms of the Creative Commons Attribution 4.0 International License (http://creativecommons.org/licenses/by/4.0/), which permits unrestricted use, distribution, and 
with Mcl-1, Bcl-XL and Bcl-2 and the pro-apoptotic proteins Bak and Bax, which lead to mitochondrial membrane potential (MMP) collapse, the release of pro-apoptotic factors and apoptosis. Overexpression of the pro-apoptotic proteins can lead to increased mitochondrial membrane collapse and release of cytochrome c, which finally can lead to ectopic apoptosis in lymphocytes [8,9].

It is well known that oncology nurses are subject to many antineoplastic drugs. Nurses are exposed to anticancer drugs during preparation and administration. Exposure to antineoplastic drugs can occur mainly to hands and occasionally to other body parts or through contact with patients treated with anti-cancer drugs via their clothing and excreta $[10,11]$. There several studies about the evaluation of anti-cancer drug apoptosis in lymphocytes of nurses [12-14]. Often these studies are focused on identifying a new diagnostic marker for nurses exposed to anti-cancer drugs in workplaces. We recently studied mitochondrial and cytotoxicity parameters in lymphocytes and isolated mitochondria of oncology nurses. Our results showed that mitochondrial toxicity and cytotoxicity parameters in the exposed group were remarkably increased compared to the unexposed group. Also, genotoxic, cytotoxicity and apoptosis monitoring in nurses handling cytotoxic drugs indicated chromosomal abnormalities, oxidative stress and cell death in the peripheral blood lymphocytes [15]. The present study focused on the analysis of apoptosisrelated genes, for this purpose, we monitored cellular toxicity parameters and gene expression in nurses who work in chemotherapy wards and compare it to nurses who work in other wards.

\section{Methods}

\section{Sample collection}

All nurses that work in chemotherapy wards of Shahid Beheshti University hospitals were chosen by entering and exit criteria by physician test. The minimum working time in the chemotherapy ward was 6 months and $45 \mathrm{~h}$ per week. Demographic data such as age, sex, time exposure, smoking status, and alcohol drinking were collected. The sample size was determined based on the power and standard deviation of variables in previous studies by power and sample size program software (50 nurses for each group).

Blood samples were collected (about $15 \mathrm{ml}$ ) in tubes containing EDTA-K2 anticoagulant agent, nurses were fasting. Control nurses who work in other wards of hospitals were chosen by the same condition as exposure nurses. All experiments were performed at Shahid Beheshti University of Medical Sciences.

\section{Isolation of lymphocytes}

The nurse's lymphocytes were isolated using the Ficoll standard method. Diluted blood samples with normal saline were layered on $3 \mathrm{ml}$ Ficoll-Paque PLUS, at 2500 rpm for $20 \mathrm{~min}$ and lymphocyte layer was centrifuged and collected, the obtained cells were suspended in erythrocyte lysis buffer (10 mM NaHCO3, $1 \mathrm{mM}$ EDTA, $150 \mathrm{mM} \mathrm{NH} 4 \mathrm{Cl}, \mathrm{pH} 7.4$ ), and incubated at $37^{\circ} \mathrm{C}$ for 5 min. The PBS was immediately added, and the lymphocytes were centrifuged at $1500 \mathrm{~g}$ and $20^{\circ} \mathrm{C}$, for $10 \mathrm{~min}$. The supernatant was discarded, and the lymphocytes were washed twice with RPMI1640. The lymphocytes were resuspended in RPMI1640 medium with 10\% FBS and L-glutamine, using trypan blue exclusion dye were counted. The cell viability was over $95 \%$ and lymphocytes were retained in a humidified atmosphere with $5 \%$ $\mathrm{CO} 2$ at $37^{\circ} \mathrm{C}$. The cell concentration used in each test was $10 \times 106$ cells $/ \mathrm{ml}$ [15].

\section{MTT assay}

The viability assessment was measured by the MTT method. The absorption of formazan dyes was read at $570 \mathrm{~nm}$ wavelength by an ELISA plate reader. All data were confirmed by using replication for at least three identical experiments [16].

\section{Annexin V/Propidium iodide staining}

Apoptosis and necrosis were determined by using the apoptosis detection kit (K101 BioVision, CA, USA). In summary, lymphocytes were resuspended in $500 \mu \mathrm{l}$ binding buffer and then FITC-conjugated Annexin V and propidium iodide (PI) were added and after 5-min incubation, samples were monitored by flow cytometer (Becton-Dickinson, USA) [17].

\section{Caspase 3 activity assay}

Activation of caspase 3 was determined in lymphocytes by Sigma's caspase- 3 assay kit (CASP-3-C). The hydrolysis of a substrate peptide, Ac-DEVD-PNA, by caspase-3 is the base of this colorimetric assay. The concentration of p-nitroaniline $(\mu \mathrm{M})$ released from the Ac-DEVD-PNA is computed from absorbance values obtained at $405 \mathrm{~nm}$ wavelength by an ELISA plate reader. Defined, pnitroaniline concentrations were used for the preparation of a calibration curve [17].

\section{ROS detection}

To measure the rate of lymphocytes ROS formation, dichlorofluoresceindiacetate (DCFH-DA, $1.6 \mu \mathrm{M}$ ) was added to the lymphocytes. The fluorescence intensity of dichlorofluorescein (DCF) was detected at excitation and emission wavelengths $490 \mathrm{~nm}$ and $525 \mathrm{~nm}$, respectively by using a fluorescence spectrophotometer [16].

\section{Lipid peroxidation assessment}

Lipid peroxidation detection in lymphocytes was performed by measuring the amount of malondialdehyde 
(MDA) during the disintegration of lipid hydroperoxides by monitoring the absorbance at $532 \mathrm{~nm}$ in a spectrophotometer [16].

\section{Lysosomal damage assay}

Lysosomal damages in lymphocytes were measured by acridine orange dye. Acridine orange that was remaining in the cell suspension was measured at $495 \mathrm{~nm}$ excitation and $530 \mathrm{~nm}$ emission wavelengths by a fluorescence spectrophotometer [16].

\section{MMP assay}

Mitochondrial uptake of Rhodamine 123 dyes $(1.5 \mu \mathrm{M})$, has been applied for estimating MMP collapse. The amount of Rhodamine 123 remaining in the incubation media was measured at $470 \mathrm{~nm}$ excitation and $540 \mathrm{~nm}$ emission wavelengths by a fluorescence spectrophotometer [16].

\section{RT-qPCR analysis}

The expression of six genes (Bcl-2, Bax, P53, TopIIa, TopIIb, and Hif-1a) was determined using RT-qPCR, primer sequences for genes shown in Table 1. Total RNA was extracted from lymphocyte samples using the RNeasy mini kit (including RNase free DNaseI) (Qiagen, Germany). Using electrophoresis in 1.2 agarose gel all extracts were qualitatively evaluated and spectrophotometrically quantitated (Ultrospec 1100, Amersham Pharmacia Biotech). $1 \mu \mathrm{g}$ of total RNA was exposed to cDNA synthesis. First-strand cDNA was produced using the RevertAid Reverse Transcriptase kit (Yekta Tajhiz Co., Iran). Primers for amplification of these genes were listed in Table 1. The real-time quantitative RT-PCR analysis and amplification of cDNA were performed using a Rotor-Gene 6000 thermocycler (Corbett Research, Australia) using an SYBR Green kit (Yekta Tajhiz Co., Iran). The thermal condition was as follows: Pre-

Table 1 Primer sequences for six genes which chosen for gene expression analysis

\begin{tabular}{|c|c|c|}
\hline Gene & Size of base pairs & Sequence of primer $5^{\prime} 3^{\prime}$ \\
\hline Bax & 155 & $\begin{array}{l}\text { F: CCCGAGAGGTCTIITTCCGAG } \\
\text { R: CCAGCCCATGATGGTTCTGAT }\end{array}$ \\
\hline$B C l-2$ & 89 & $\begin{array}{l}\text { F: GGTGGGGTCATGTGTGTGTGG } \\
\text { R: CGGTTCAGGTACTCAGTCATCC }\end{array}$ \\
\hline P53 & 181 & $\begin{array}{l}\text { F: GTCTGGGCTTCTTGCATT } \\
\text { R: GTCATGTGCTGTGACTGC }\end{array}$ \\
\hline ACTB & 138 & $\begin{array}{l}\text { F: AACGGTGAAGGTGACAGCAGTCG } \\
\text { R: GGCAAGGGACTTCCTGTAACAACG }\end{array}$ \\
\hline Hif-1a & 164 & $\begin{array}{l}\text { F: ACAGCCTCAGGAAACAGAGCAGG } \\
\text { R: CGCTITCTCTGAGCATITGCAAAGC }\end{array}$ \\
\hline Topolla & 175 & $\begin{array}{l}\text { F: GAATCAGATAGGAGCAGTGACG } \\
\text { R: GTGGACTAGCATCTGATGGGAC }\end{array}$ \\
\hline Topollb & 182 & $\begin{array}{l}\text { F: GCACTGACCTGGGTGAACAA } \\
\text { R: ACCCACATGAACTGCGTCAA }\end{array}$ \\
\hline
\end{tabular}

denaturation at $95^{\circ} \mathrm{C}$ for $5 \mathrm{~min}$, denaturation at $95^{\circ} \mathrm{C}$ for $10 \mathrm{~s}$, annealing at $60^{\circ} \mathrm{C}$ for $20 \mathrm{~s}$, extension at $70^{\circ} \mathrm{C}$ for $20 \mathrm{~s}, 40$ cycles in total. $\beta$-actin was used as a housekeeping gene to normalize the cDNA variation. Relative quantification was made using the Pffafl method (16). Each experiment was repeated three times [18].

\section{Statistical analysis}

The unpaired T- test was used to compare the results between two nurses' groups using GraphPad Prism 7 software, with $P<0.05$ being significant. For RT-qPCR, relative quantification was made using the Pffafl method and another analysis was performed by the Two-way ANOVA test and Bonferroni post-test. Based on pffafle analysis, a ratio above 2 is considered as Overexpression and below 0.5 as Low Expression.

\section{Results}

\section{Demographic data}

Important demographic data were shown in Table 2. $83.33 \%$ of nurses were women and $16.67 \%$ were men in both groups. The average age of oncology nurses was 29.27 years and in the control group were 28.69 years. Control nurses never work in the oncology ward and an average of times of exposure to oncology nurses was 27.43 months. A series of general clinical symptoms, including a headache, eye irritation, skin irritation, dizziness, dyspnea, chest pain, sleep problems, and nausea were evaluated in nurses in both control and exposed groups. All of the above-mentioned symptoms were higher in nurses in the exposed group, but most of these nurses complained of skin irritation, dizziness, a headache, and heavy headache (Fig. 1).

\section{Viability assessment}

According to Fig. 2, the lymphocyte viability of oncology nurses was significantly lower than those of control nurses $(p<0.001)$.

\section{Apoptosis assay}

Using cell flow cytometry and AnnexinV-PI staining, cell status was determined for apoptosis and necrosis in control and exposed groups. According to the data, lymphocytes which were at apoptosis state in chemotherapy nurses were more than in control nurses $(P<0.001)$ which are shown in Fig. 3. Quadrant 1 includes necrosis cells (Annexin V-/PI+), Quadrant 2 includes cells under secondary necrosis or late apoptosis (Annexin $\mathrm{V}+/ \mathrm{PI}+$ ), Quadrant 3 includes live cells (Annexin V-/PI-) and Quadrant 4 includes cells under early apoptosis (Annexin V+/PI-). 
Table 2 The demographic characteristics of study nurses

\begin{tabular}{lll}
\hline & Control nurses & Oncology nurses \\
\hline Male & $16.67 \%$ & $16.67 \%$ \\
Female & $83.33 \%$ & $83.33 \%$ \\
Smoking & 0 & 0 \\
Alcohol drinking & 0 & 0 \\
Average of age (year) & $28.69 \pm 4.008$ & $29.27 \pm 3.693$ \\
Average time of work in oncology ward (month) & 0 & $25.43 \pm 27.73$ \\
Antioxidant therapy intake & $>1 \%$ & $>1 \%$ \\
Use of personal protection tools & $99 \%$ & $99 \%$ \\
Interference in preparation drug stage & $100 \%$ & 0 \\
Pregnance nurses (number) & 0 & $2^{*}$
\end{tabular}

*pregnancy nurses removed from this study

\section{Activation of Caspase 3}

The activity of caspase 3 in cytoplasm starts a process that leads to apoptosis in cells. This activation was measured by a substrate of caspase 3 . Figure 4a shows that the activity of caspase 3 in lymphocytes isolated from oncology nurses has been signed $(p<0.001)$ higher than that of control nurses.

\section{Measurement of ROS formation}

Disruption of the balance between cellular ROS formation and endogenous antioxidants can start oxidative stress in cells. Our results show that the amounts of ROS formation in lymphocytes of oncology nurses were significantly $(\mathrm{p}<$ 0.001) higher than those of control nurses (Fig. 4b).

\section{Lipid peroxidation in isolated lymphocytes}

Lipid peroxidation was determined by measuring the amount of malondialdehyde (MDA) in isolated lymphocytes. As shown in Fig. 4c, lymphocytes of oncology nurses have significantly $(p<0.001)$ higher than MDA compared to those of control nurses.

\section{Lysosomal membrane integrity.}

Lysosomal integrity was determined by Acridine Orange fluorescent dye redistribution in lymphocytes isolated

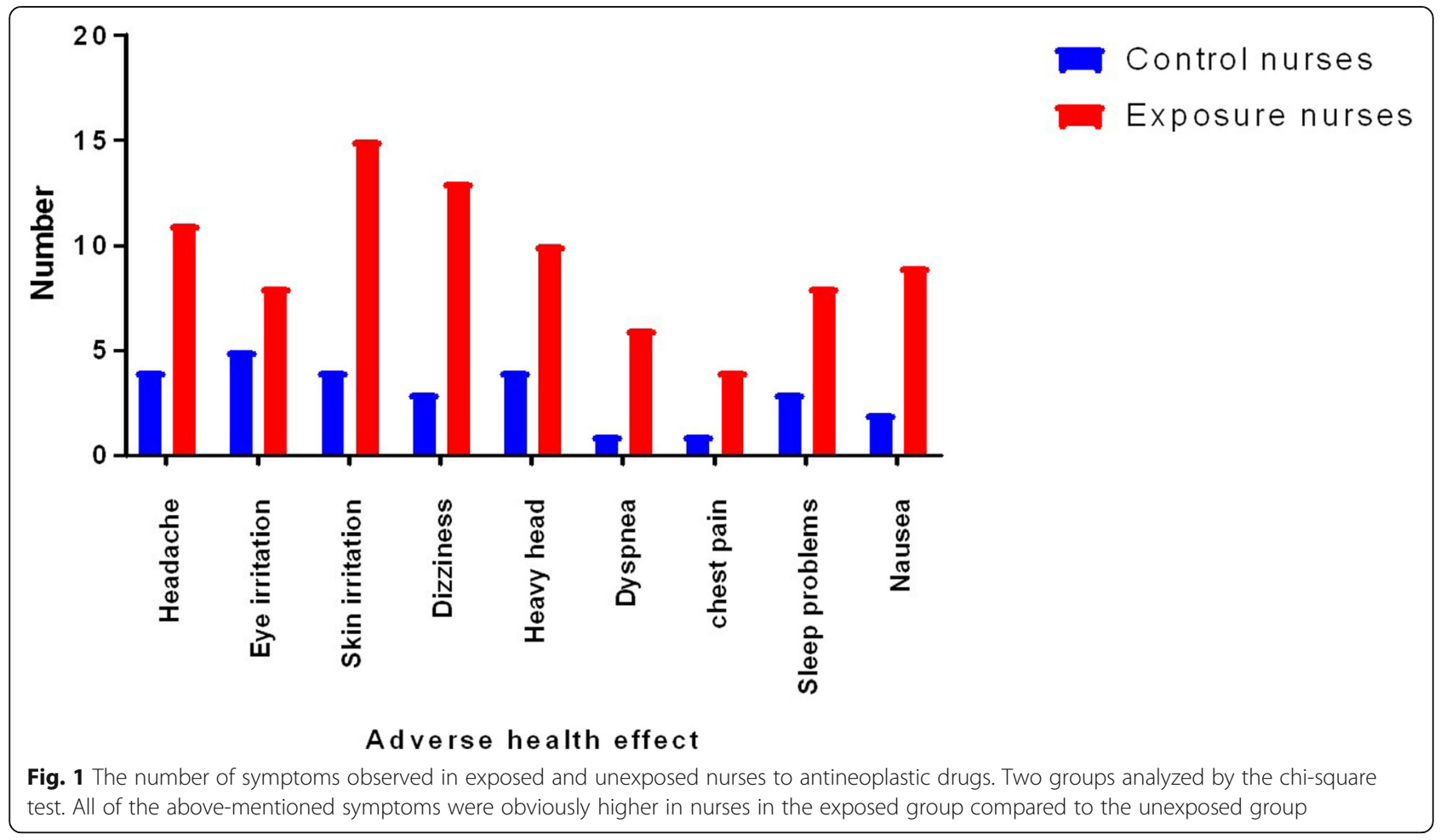




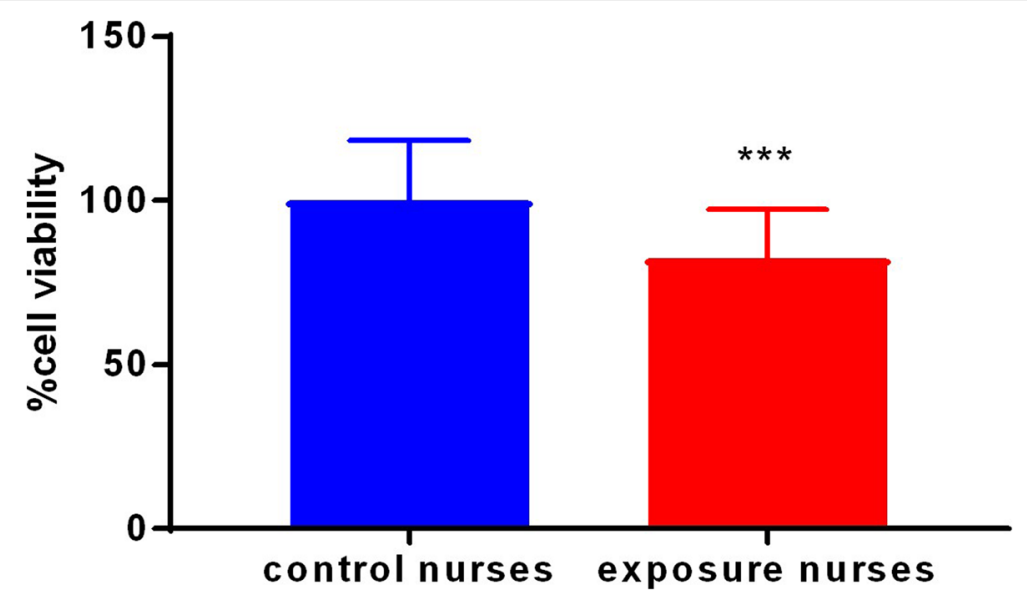

Fig. 2 The viability of lymphocytes isolated in exposed and control nurses, cell viability were significantly higher in nurses in the exposed group compared to the unexposed group. Values (mean \pm SD) are from three independent experiments $(n=3)$. ${ }^{* *} p<0$. 001. Results are expressed as means $\pm S D, n=50$

from the nurse's blood. The results of the lysosomal integrity test show that nurses who work in the oncology ward have higher lysosomal membrane damage compared to those of control nurses (Fig. 5a) $(p<0.001)$.

\section{Mitochondrial membrane potential collapse}

To understand changes in mitochondrial membrane potential, we used Rhodamine 123 dye. When the fluorescence intensity related to Rhodamine 123 release from mitochondria into the cytosol, is high, it means that the loss of mitochondrial membrane potential is also high. Our results showed that lymphocytes of oncology nurses demonstrate more decline in mitochondrial membrane potential rather than those of control nurses (Fig. 5b) $(p<0.001)$.

Determination of Bax, Bcl-2, P53, Hif-1a, topoisomeraseIla and topoisomerase-llb level

Relative expression levels of six genes with central roles in the regulation of apoptosis, chromosome segregation, transcription, DNA repair, and glucose metabolism were analyzed by RT-qPCR in two groups of nurses (oncology and controls). Data analysis of 50 exposed nurses demonstrated reduced $\mathrm{Bcl}-2$ expression (significantly reduced expression value, less than 0.5$)$ in 20 cases (40\%) and increased $\mathrm{Bcl}-2$ expression in 15 cases (30\%) (not significantly overexpression, a value less than 2 ) and

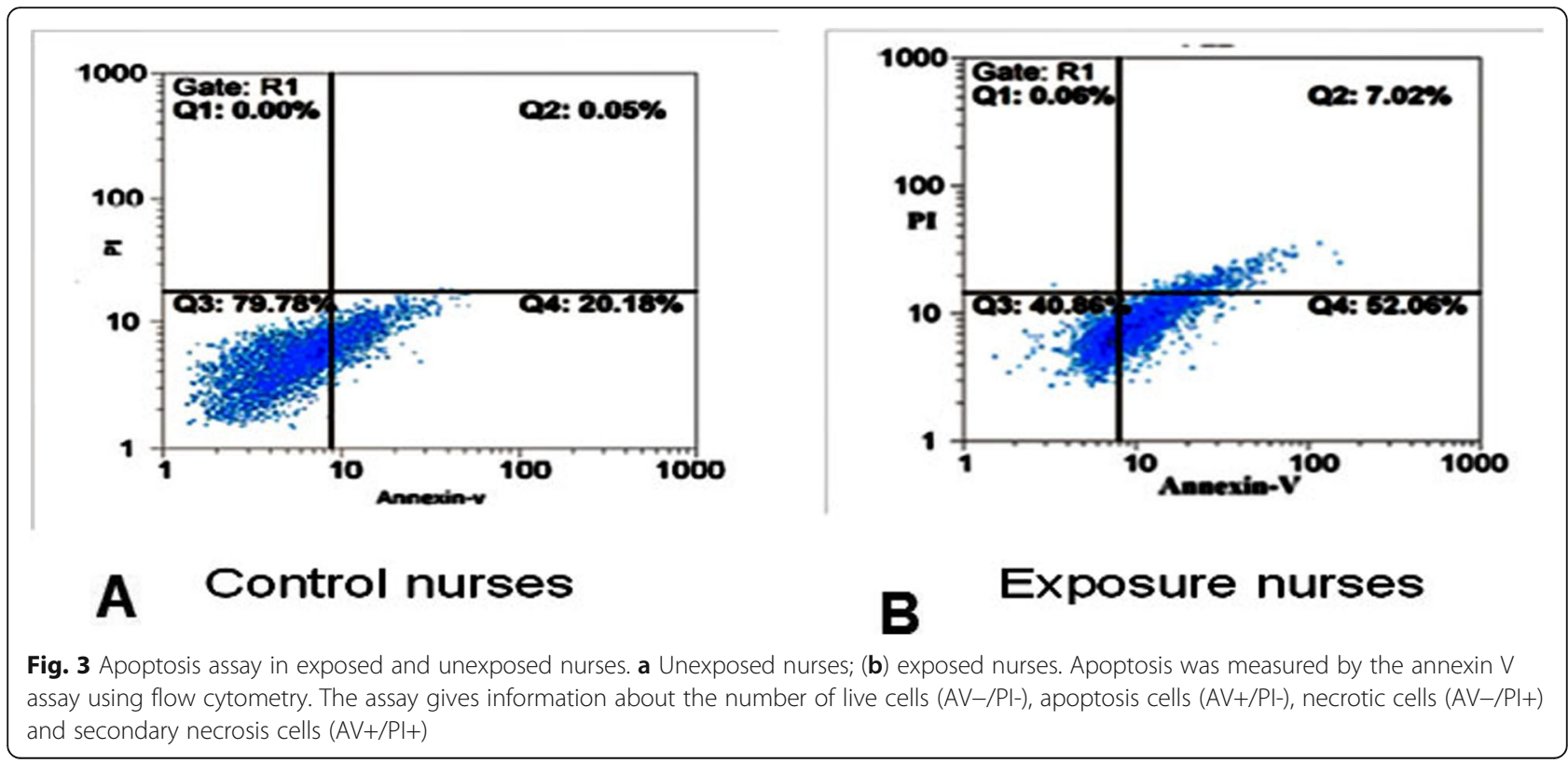


A

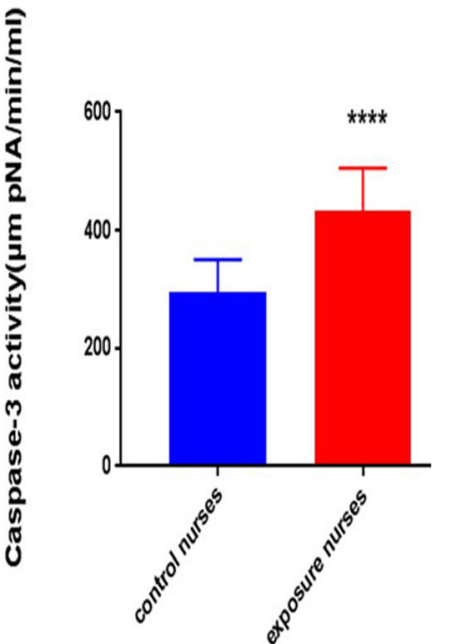

B

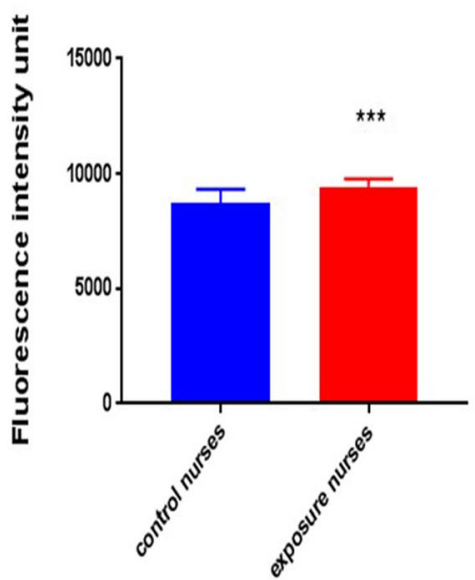

C

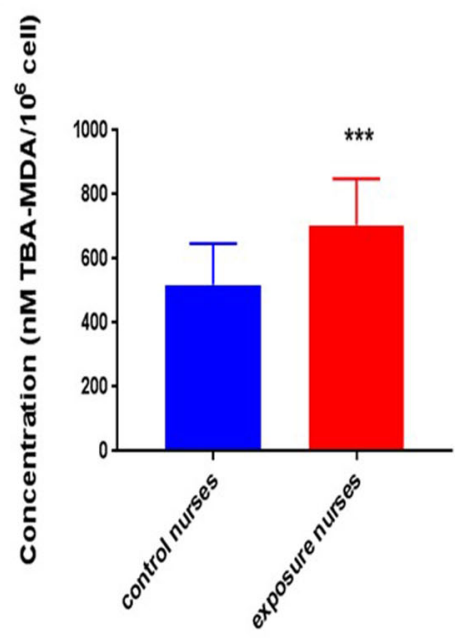

Fig. 4 Caspase-3 activity (a). ROS formation was measured (b). Malondialdehyde amounts formed during the decomposition of lipid hydroperoxides $(\mathbf{c})$. All of them was significantly higher in nurses in the exposed group compared to the unexposed group. ${ }^{* *} p<0.001{ }^{* * *} p<0$. 0001. Results are expressed as means \pm SD

approximately equal expression of $\mathrm{Bcl}-2$ (normal expression) in 15 remaining cases (30\%). The expression of this gene was nearly the same in cases in the control group. A comparison of the average expression of $\mathrm{Bcl}-2$ in two groups did not show a significant difference between them $(p>0.05)$. Whereas the expression of $\mathrm{Bax}$ increased significantly $(P<0.05)$ in 20 cases $(40 \%)$ and the remaining was nearly the same in the rest of exposed nurses. Cases in the control group showed normal similar expression. A comparison of the average expression of $\mathrm{Bax}$ in two groups did not show a significant difference between them $(p>0.05)$. The real-time PCR data demonstrated increased expression of Bax: $\mathrm{Bcl}-2$ ratio of $40 \%$ of exposed nurses as compared with control ones. The average expression of $\mathrm{Bax}$ : $\mathrm{Bcl}-2$ ratio of exposed nurses was significantly different from that in the control group $(\mathrm{P}<0.05)$. P53 was overexpressed in 20 cases (40\%) in the exposed group. The average expression of P53 in exposed nurses was significantly different from that in the control group. It is expected that the expression of wild type Top $2 \alpha$ and Top $2 \beta$ decreases in chemotherapeutic resistant tumor cells. However, these two genes expressed similarly in two groups. The average expression of both genes in exposed nurses was not significantly different from that in the control group. It was shown that Hif- $1 \alpha$ overexpresses in chemotherapeutic resistant tumor cells, especially in acute lymphoblastic leukemia (ALL) and acute myeloid leukemia (AML). Whereas Hif- $1 \alpha$ neither overexpressed nor showed a significant difference in two groups (Fig. 6).
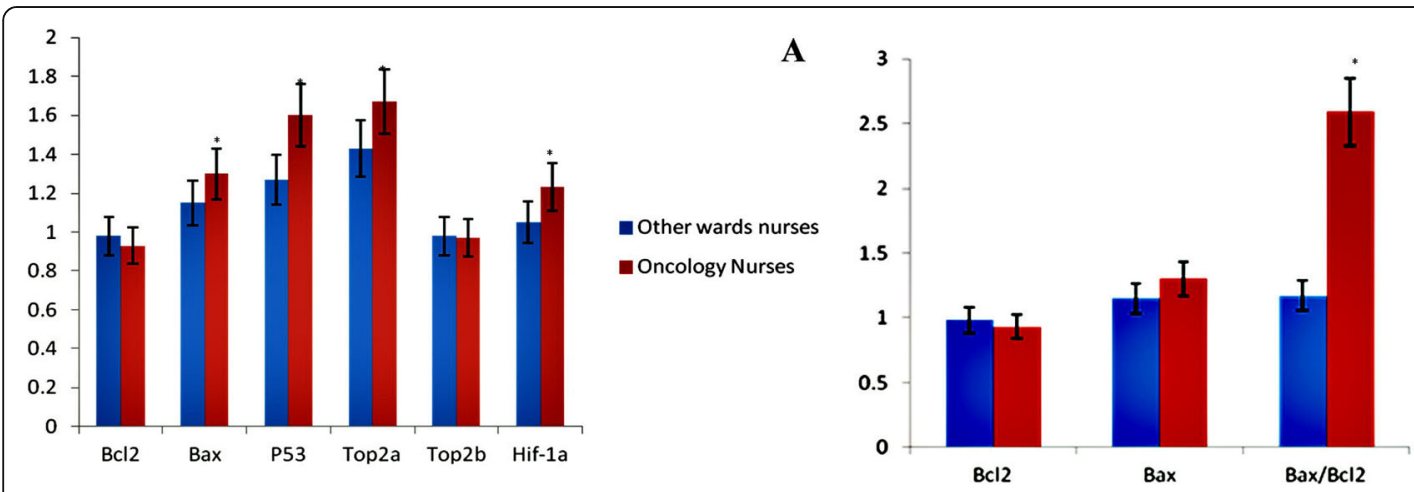

B

Fig 5 Lysosomal membrane damage (a). MMP collapse. b. Two parameters were significantly higher in nurses in the exposed group compared to the unexposed group Each bar represents mean $\pm \mathrm{SD}(n=50) .{ }^{* * *} p<0.0001$ significant differences compared to the unexposed group 


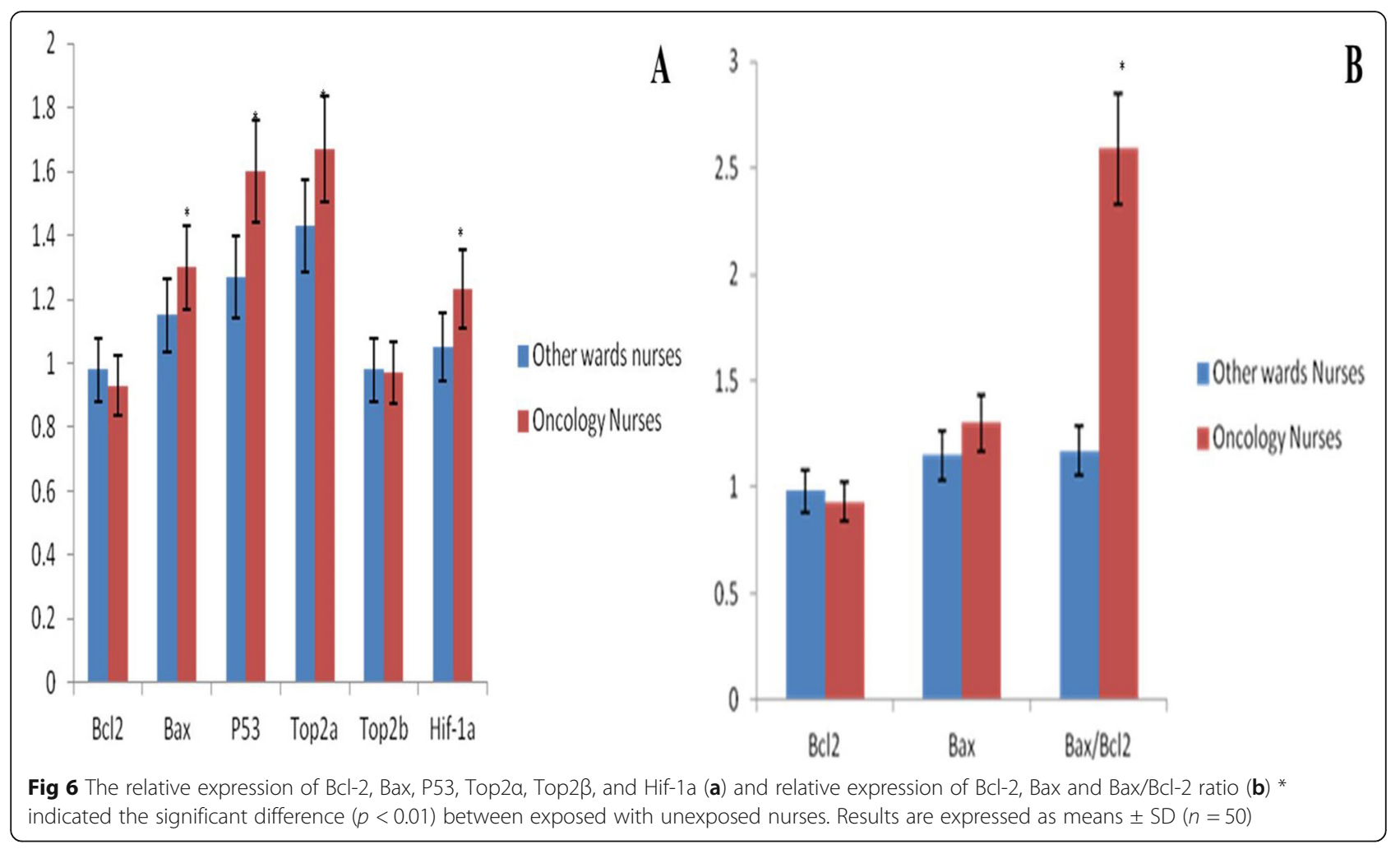

\section{Discussion}

We previously reported the results of mitochondrial toxicity and oxidative stress parameters in nurses that have been occupationally exposed to antineoplastic drugs [15]. In the current study, we searched apoptosis and expression of apoptosis-related genes in the same set of the antineoplastic drug-exposed nurses. According to biochemical observations, the obtained results in our study showed that the mitochondrial toxicity and oxidative stress parameters in the lymphocytes of nurses in the oncology ward are higher than significantly compared with other nurses. We confirmed that apoptosis in antineoplastic drug-exposed nurses was higher than unexposed nurses with antineoplastic drugs (Fig. 3).

Bcl-2 family proteins have a key role in the regulation of cell death [19]. There two types of proteins in this family, including the pro-survival subfamily like Bcl-2 band the pro-apoptotic subfamily such as Bax [20]. Antiapoptotic $\mathrm{Bcl}-2$ family members support the viability of cells by binding to multidomain pro-apoptotic members and inhibiting apoptotic activities of them. However, multidomain pro-apoptotic Bcl-2 family members attack the mitochondria and lead to mitochondrial outer membrane permeability and apoptosis [21]. In this study, we showed that exposed nurses with antineoplastic drugs have higher pro-apoptotic $\mathrm{Bcl}-2$ proteins than unexposed nurses (Fig. 6). These data are correlated with the induction of apoptosis, cytotoxicity and mitochondrial membrane potential collapse. Cellular ROS formation can be reduced by Bcl-2. Antioxidant effects of Bcl-2 are shown by previously published studies. These studies suggested that the pro-survival $\mathrm{Bcl}-2$ family decrease glutathione depletion in cells [22, 23]. We observed a higher level of ROS formation in the exposed nurses compared with unexposed nurses. The obtained results suggested that a decrease in pro-survival Bcl-2 is effectively in ROS content in exposed nurses. Deactivation of the anti-apoptotic $\mathrm{Bcl}-2$ family members leads to activation of the pro-apoptotic Bcl-2 such as Bak and Bax, these occurrences are thought to happen in parallel, finally resulting in cytochrome c release through MMP collapse, activation of caspases and apoptosis [21, 24]. Our results showed that an increase in $\mathrm{Bax} / \mathrm{Bcl}-2$ is accompanied by an MMP collapse in mitochondria, activation of caspase 3 and apoptosis in exposed nurses (Figs. 3, 4A and 5B).

Hif- $1 \alpha$ is remarked as the master transcriptional controller of development and cellular reply to hypoxia. The overexpression and dysregulation of Hif- $1 \alpha$ by genetic alternations or hypoxia have been involved in the biology of cancer, specifically in areas of energy metabolism, angiogenesis and vascularization, tumor invasion and cell survival [25]. A recent study showed that Hif- $1 \alpha$ is recruited to mitochondria in answer to oxidative stress and safeguards against oxidative stress-induced apoptosis. In mitochondria, Hif- $1 \alpha$ decreases ROS levels and 
reverses mitochondrial damage [26]. Also, previous studies showed that HIF- $1 \alpha$ decreases ROS formation via multiple pathways and reverses mitochondrial damage [27]. Our results here suggest that probably overexpression of Hif- $1 \alpha$ in exposed nurses is for inhibition of mitochondrial and oxidative damage induced by exposing antineoplastic drugs.

Tumor suppressor P53 is a transcription factor that controls cell growth [28]. New investigations showed that P53 can lead to changing from normal to an abnormal condition under different stress conditions in mitochondria. When stress stimuli occur, like exposure to antineoplastic in our study, ROS promote P53 to repair dysfunctional mitochondria to finish mitochondrial degradation [29]. If damage or stress is irreversible, P53 will translocate to mitochondria, leading into necrosis or apoptosis [30].

Topoisomerase II is a type II DNA topoisomerase that has been reported to be expressed in all mammalian cells, but is widely expressed in cells that are differentiating for achieving post-mathisophytic status. Topoisomerase II plays an important role in various biological areas such as transcription, DNA repair, neurodegeneration, aging, HIV infection and cancer [31-35]. Exposure to anti-cancer drugs, especially those targeting DNA topoisomerases may change the expression pattern of Top $2 \alpha$ and Top $2 \beta$ genes [36]. We did not find a significant difference in expression of these genes in two groups $(P>0.05)$ and both groups showed normal expression. Additionally, exposure to these drugs may cause resistance against them. Hif- $1 \alpha$ can be used as a biomarker that shows resistance as its expression enhances in resistant cells [37]. Neither of the groups showed overexpression of this gene and a significant difference in the level of expression $(P<0.05)$.

We couldn't detect all chemotherapy drugs concentration in the blood of nurses because the number of drugs that are in use in chemotherapy wards of our country Iran are more than 40 different drugs and measurement of their exact concentration in the blood sample is not possible at the same time. Besides, these drugs have synergistic and antagonistic effects on each other. Therefore, the presence or absence of a single drug in blood at the time of measurement is not a reason for the absence or present of adverse effects.

\section{Conclusions}

In summary, the results of the current study showed that oxidative stress and mitochondrial toxicity induced by antineoplastic drugs lead to overexpression of apoptosisrelated genes in human lymphocytes.

\section{Abbreviations}

DCF: Dichlorofluorescein; DCFH-DA: Dichlorofluorescein Diacetate; IARC: International Agency for Research on Cancer; MDA: Malondialdehyde: MMP: Mitochondrial Membrane Potential; ROS: Reactive Oxygen Species

\section{Acknowledgments}

The authors acknowledged all the members for giving their time to participate in the study.

\section{Authors' contributions}

MR and RPJ participated collected and analyzed the data and participated in drafting the manuscript; AS participated in analysing the data as the statistical advisor and drafting the manuscript; JP participated in designing the study, formolating the reseach, writting the manuscript and supervising the thesis cand FHS co supervised the thesis; MTA participated as clinical advisor of the study. All authors read and approved the final manuscript.

\section{Funding}

This study was supported by Shahid Beheshti University of Medical Sciences, Deputy of Research Grant No. 10805. The funder had no the role in the design of the study and collection, analysis, and interpretation of data and in writing the manuscript.

\section{Availability of data and materials}

All data and materials related to the study can be obtained in the Materials and Methods Section.

\section{Ethics approval and consent to participate}

All volunteers signed an informed consent form and this study was authorized by Shahid Beheshti University of Medical Sciences.

\section{Consent for publication}

Not applicable.

\section{Competing interests}

All authors report no competing interests relevant to this study. We declare that Dr. Ahmad Salimi is a member of your Editorial board.

\section{Author details}

'Department of Pharmacology and Toxicology, Faculty of Pharmacy, Shahid Beheshti University of Medical Sciences, Tehran, Iran. ${ }^{2}$ Department of Genetics, Faculty of Sciences, Shahr-e-Kord University, Shahr-e-Kord, Iran. ${ }^{3}$ Department of Clinical Pharmacy, Faculty of Pharmacy, Shahid Beheshti University of Medical Sciences, Tehran, Iran. ${ }^{4}$ Department of Pharmacology and Toxicology, School of Pharmacy, Ardabil University of Medical Sciences, Ardabil, Iran. ${ }^{5}$ Pharmaceutical Sciences Research Center, Shahid Beheshti University of Medical Sciences, Tehran, Iran.

Received: 3 July 2019 Accepted: 8 November 2019

Published online: 02 December 2019

\section{References}

1. Chabner BA, Roberts TG Jr. Chemotherapy and the war on cancer. Nat Rev Cancer. 2005;5(1):65

2. Rombaldi F, Cassini C, Salvador M, Saffi J, Erdtmann B. Occupational risk assessment of genotoxicity and oxidative stress in workers handling antineoplastic drugs during a working week. Mutagenesis. 2008;24(2):143-8.

3. Mahmoodi M, Soleyman-Jahi S, Zendehdel K, Mozdarani H, Azimi C, Farzanfar F, Safari Z, Mohagheghi M-A, Khaleghian M, Divsalar K. Chromosomal aberrations, sister chromatid exchanges, and micronuclei in lymphocytes of oncology department personnel handling anti-neoplastic drugs. Drug Chem Toxicol. 2017;40(2):235-40.

4. Humans IWGotEoCRt, Cancer IAfRo, Organization WH: IARC monographs on the evaluation of carcinogenic risks to humans, vol. 51: world health Organization; 1991.

5. Marselos M, Vainio H. Carcinogenic properties of pharmaceutical agents evaluated in the IARC monographs program. Carcinogenesis. 1991;12(10): 1751-66.

6. Manda G, Nechifor MT, Neagu T-M. Reactive oxygen species, cancer, and anti-cancer therapies. Curr Chem Biol. 2009;3(1):22-46.

7. Fulda S, Gorman AM, Hori O, Samali A. Cellular stress responses: cell survival and cell death. Int I Cell Biol. 2010:2010.

8. Liu B, Chen Y, Clair DKS. ROS and p53: a versatile partnership. Free Radic Biol Med. 2008:44(8):1529-35

9. Vaseva AV, Moll UM. The mitochondrial p53 pathway. BiochimicaetBiophysicaActa (BBA)-Bioenergetics. 2009;1787(5):414-20. 
10. Ramphal R, Bains T, Vaillancourt R, Osmond MH, Barrowman N. Occupational exposure to cyclophosphamide in nurses at a single center. J Occup Environ Med. 2014;56(3):304-12.

11. Vallerand AH: Davis's drug guide for nurses: FA Davis; 2018

12. Liao H, Bi L, Wei J, Song X. Evaluation of apoptosis induced by exposure to antineoplastic drugs in peripheral blood lymphocytes of nurses. Mol Med Rep. 2017;16(6):8103-9.

13. Tompa A, Biró A, Jakab M. Genotoxic monitoring of nurses handling cytotoxic drugs. Asia Pac J Oncol Nurs. 2016;3(4):365.

14. Yoshida J, Kosaka H, Tomioka K, Kumagai S. Genotoxic risks to nurses from contamination of the work environment with antineoplastic drugs in Japan. J Occup Health. 2006;48(6):517-22.

15. Eghbal MA, Yusefi E, Tavakoli-Ardakani M, Ramazani M, Zarei MH, Salimi A, Pourahmad J. Exposure to antineoplastic agents induces cytotoxicity in nurse lymphocytes: role of mitochondrial damage and oxidative stress. Iran J Pharmaceutical Res. 2018;17(Suppl):43.

16. Pourahmad J, Eskandari MR, Nosrati M, Kobarfard F, Khajeamiri AR. Involvement of mitochondrial/lysosomal toxic cross-talk in ecstasy induced liver toxicity under hyperthermic condition. Eur J Pharmacol. 2010;643(2-3): 162-9.

17. Salimi A, Roudkenar MH, Seydi E, Sadeghi L, Mohseni A, Pirahmadi N, Pourahmad J. Chrysin as an anti-cancer agent exerts selective toxicity by directly inhibiting mitochondrial complex II and V in CLL B-lymphocytes. Cancer Investig. 2017;35(3):174-86.

18. Pfaffl MW. A new mathematical model for relative quantification in real-time RT-PCR. Nucleic Acids Res. 2001;29(9):e45-5.

19. Um H-D. Bcl-2 family proteins as regulators of cancer cell invasion and metastasis: a review focusing on mitochondrial respiration and reactive oxygen species. Oncotarget. 2016;7(5):5193.

20. Ola MS, Nawaz M, Ahsan H. Role of Bcl-2 family proteins and caspases in the regulation of apoptosis. Mol Cell Biochem. 2011;351(1-2):41-58.

21. Susnow $\mathrm{N}$, Zeng L, Margineantu D, Hockenbery DM: Bcl-2 family proteins as regulators of oxidative stress. In: Seminars in cancer biology: 2009. Elsevier: 42-49.

22. Kane DJ, Sarafian TA, Anton R, Hahn H, Gralla EB, Valentine JS, Ord T, Bredesen DE. BCl-2 inhibition of neural death: decreased generation of reactive oxygen species. Science. 1993;262(5137):1274-7.

23. Gupta S, Yel L, Kim D, Kim C, Chiplunkar S, Gollapudi S. Arsenic trioxide induces apoptosis in peripheral blood T lymphocyte subsets by inducing oxidative stress: a role of Bcl-2. Mol Cancer Ther. 2003;2(8):711-9.

24. Shangary $\mathrm{S}$, Johnson DE. Peptides derived from $\mathrm{BH} 3$ domains of $\mathrm{BCl}-2$ family members: a comparative analysis of inhibition of $\mathrm{BCl}-2, \mathrm{BCl}-\mathrm{xL}$ and Baxoligomerization, induction of cytochrome $\mathrm{c}$ release, and activation of cell death. Biochemistry. 2002;41(30):9485-95.

25. Ke Q, Costa M. Hypoxia-inducible factor-1 (HIF-1). Mol Pharmacol. 2006;70(5): $1469-80$.

26. Li H-S, Zhou Y-N, Li L, Li S-F, Long D, Chen X-L, Zhang J-B, Feng L, Li Y-P. HIF-1a protects against oxidative stress by directly targeting mitochondria. Redox Biol. 2019;101109.

27. Tormos KV, Chandel NS. Inter-connection between mitochondria and HIFs. J Cell Mol Med. 2010;14(4):795-804.

28. Jones RG, Thompson CB. Tumor suppressors and cell metabolism: a recipe for cancer growth. Genes Dev. 2009;23(5):537-48.

29. Montero J, Dutta C, Van Bodegom D, Weinstock D, Letai A. p53 regulates a non-apoptotic death induced by ROS. Cell Death Differ. 2013;20(11):1465.

30. Dai C-Q, Luo T-T, Luo S-C, Wang J-Q, Wang S-M, Bai Y-H, Yang Y-L, Wang YY. p53 and mitochondrial dysfunction: novel insight of neurodegenerative diseases. J Bioenerg Biomembr. 2016;48(4):337-47.

31. Yang X, Li W, Prescott ED, Burden SJ, Wang JCJS: DNA topoisomerase II and neural development 2000, 287(5450):131-134.

32. Ju B-G, Lunyak W, Perissi V, Garcia-Bassets I, Rose DW, Glass CK, Rosenfeld MGJs: A topoisomerase IIß-mediated dsDNA break required for regulated transcription 2006, 312(5781):1798-1802.

33. Lyu YL, Lin C-P, Azarova AM, Cai L, Wang JC, Liu LFJM, Biology c: Role of topoisomerase $\| \beta$ in the expression of developmentally regulated genes 2006, 26(21):7929-7941.

34. Popanda O, Thielmann HWJC: The function of DNA topoisomerases in UVinduced DNA excision repair: studies with specific inhibitors in permeabilized human fibroblasts. 1992, 13(12):2321-2328.

35. Bollimpelli VS, Dholaniya PS, KondapiAKJAob, biophysics: Topoisomerase iiß and its role in different biological contexts 2017, 633:78-84.
36. Kanagasabai R, Serdar L, Karmahapatra S, Kientz CA, Ellis J, Ritke MK, Elton TS, YalowichJCJJoP, Therapeutics E: Alternative RNA processing of topoisomerase Ila in etoposide-resistant human leukemia K562 cells: intron retention results in a novel C-terminal truncated 90-kDa isoform. 2017, 360(1):152-163.

37. Song K, Li M, Xu X-J, Xuan L, Huang G-N, Song X-L, Liu Q-FJAPJCP: HIF-1a and GLUT1 gene expression are associated with chemoresistance of acute myeloid leukemia. 2014, 15(4):1823-1829.

\section{Publisher's Note}

Springer Nature remains neutral with regard to jurisdictional claims in published maps and institutional affiliations.
Ready to submit your research? Choose BMC and benefit from:

- fast, convenient online submission

- thorough peer review by experienced researchers in your field

- rapid publication on acceptance

- support for research data, including large and complex data types

- gold Open Access which fosters wider collaboration and increased citations

- maximum visibility for your research: over $100 \mathrm{M}$ website views per year

At BMC, research is always in progress.

Learn more biomedcentral.com/submissions 